\title{
Synthesis and Properties of Polycarbosilanes by Hydrosilylation Polymerization
}

\author{
Manabu Tsumura,* Takahisa Iwahara, and Toshifumi Hirose \\ Kohe Laboratories, Research Institute, Kaneka Corporation, \\ 1-2-80. Yoshida-cho, Hyogo-ku, Kobe 652, Japan
}

(Received March 24, 1995)

\begin{abstract}
KEY WORDS Polycarbosilane / Hydrosilylation / Thermal Stability / Solubility / Vinyl End-blocked Polycarbosilane / Asymmetry of Substituents / Molecular Weight Control
\end{abstract}

Hydrosilylation polymerization has been reported as the well-known reaction which led to polycarbosilanes (PCS) ${ }^{1,2}$ (Scheme 1) and related polymers. ${ }^{3-5}$ However, much attention was not paid to the physical properties of the polycarbosilanes thus prepared.

For instance, the synthesis of PCS $1\left(\mathrm{R}^{1}=\right.$ $\mathrm{Si}(\mathrm{Ph})(\mathrm{Me})-\mathrm{Ar}-, \mathrm{R}^{2}=\mathrm{Ph}, \mathrm{R}^{3}=\mathrm{Me} ; \mathrm{Pt} / \mathrm{C}$ cat.; $300^{\circ} \mathrm{C}$ ) was reported by Znamenskaya and co-workers in $1964^{2}$ (Scheme 1). Under the severe reaction conditions, the yield of PCS 1 was only $30 \%$, the number-average molecular weight $\left(M_{n}\right)$ was around 3000 , and the physical properties were not investigated at all.

We recently reported that PCS 2 could be synthesized at room temperature by hydrosilylation polymerization in the presence of the platinum catalyst $\left[\mathrm{Pt}\left\{\left(\mathrm{CH}_{2}=\mathrm{CHSiMe}\right)_{2} \mathrm{O}\right\}_{2}\right]^{6,7}$ (Scheme 2). ${ }^{8}$ In the synthetic reaction in toluene, PCS 2 was precipitated because of the PCS 2's low solubility. Actually, minimum solvent volume required for dissolving $1 \mathrm{~g}$ of PCS 2 was above $200 \mathrm{ml}$ at $15-20^{\circ} \mathrm{C}$ (Table II), and the solubility for the low-molecularweight derivatives of PCS $2\left(M_{n}=\sim 10^{3}\right)$ was low, too. The low solubility seems to be a disadvantage on moldability, such as spinning fibers, forming films, and making a solution for prepregs etc., and also on improvement of physical properties by curing reaction. However the thermal stability of PCS 2 was good (Table II). Our previous work made clear that the unit of $\left[-\mathrm{Me}_{2} \mathrm{Si}-p-\mathrm{C}_{6} \mathrm{H}_{4}-\mathrm{Me}_{2} \mathrm{Si}-\right.$ $\mathrm{CH}_{2} \mathrm{CH}_{2}-$ ] was necessary unit for good thermal stability.

We designed the PCS 1a-c which was expected to have high solubility owing to the

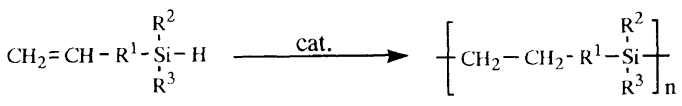

Scheme 1.

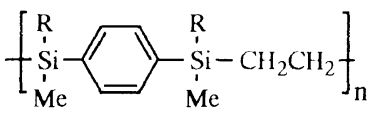

$$
\text { 1a }-\mathbf{c}: \mathrm{R}=\mathrm{Ph}
$$$$
\text { 2: } \mathrm{R}=\mathrm{Me}
$$

Scheme 2.

* To whom correspondence should be addressed. 
asymmetry of their substituents still maintaining good thermal stability because of its backbone structure (Scheme 2).

In this paper, we investigated the synthesis and properties of PCS $1 \mathbf{a}-\mathbf{c}$ and vinyl-end blocked PCS 1c.

\section{EXPERIMENTAL}

\section{Materials and Instruments}

Diethoxymethylphenylsilane, 1,4-dibromobenzene, $\mathrm{Mg}$, and vinylmagnesium-bromide were purchased from commercial sources. Tetrahydrofuran and toluene were dried over $\mathrm{Na}$ / bezophenone and were distilled before use. The platinum catalyst $\left[\mathrm{Pt}\left\{\left(\mathrm{CH}_{2}=\mathrm{CHSiMe}_{2}\right)_{2} \mathrm{O}\right\}_{2}\right]$ (1.0 $\mathrm{wt} \%$ xylene solution) was prepared by the reaction of $\mathrm{H}_{2} \mathrm{PtCl}_{6} \cdot \mathrm{H}_{2} \mathrm{O}$ and 1,1,3,3-tetramethyl-1,3-divinyldisiloxane.

${ }^{1} \mathrm{H},{ }^{13} \mathrm{C},{ }^{29} \mathrm{Si}$ NMR spectra were recorded in $\mathrm{CDCl}_{3}$ on a Varian Gemini 300 instrument. Mass spectra were obtained on a Shimadzu GCMS QP-2000A. Gel permeation chromatographic analyses (GPC) were carried out on Waters LC Module with Shodex 804 by using chloroform as an eluent after calibration with standard polystyrene samples. Thermogravimetric analyses (TGA) were made on a Shimazu TGA50 instrument $\left(20^{\circ} \mathrm{C} \mathrm{min}{ }^{-1}\right)$ under nitrogen stream $\left(30 \mathrm{ml} \mathrm{min}^{-1}\right)$.

\section{Preparations of $\mathbf{3}$ and $\mathbf{5}$ (Scheme 3)}

The preparations of $\mathbf{3}$ and $\mathbf{5}$ were carried out according to the methods previously reported. ${ }^{9,10}$

\section{Preparation of 4 (Scheme 3)}

In a 100 -ml two-neck pear-shape flask equipped with a teflon-covered magnetic stirring bar, a dropping funnel, and a reflux condenser were placed $3(5.0 \mathrm{~g}, 12.3 \mathrm{~mol})$ and tetrahydrofuran (THF) $(20 \mathrm{ml})$. A THF solution $(1.0 \mathrm{M}, 27.1 \mathrm{ml})$ of vinylmagnesiumbromide was placed in the dropping funnel. The reaction mixture was stirred while the solution of vinylmagnesiumbromide was added over
$45 \mathrm{~min}$. After the addition the mixture was stirred for $3 \mathrm{~h}$ under reflux and for $16 \mathrm{~h}$ at room temperature. Hexane and water were added to reaction mixture. The organic layer was separated and washed with brine. The organic layer was dried over anhydrous sodium sulfate, then filtered, and the solvents were removed by evaporation under reduced pressure. Kugelrohr distillation $(0.5 \mathrm{mmHg}, 180$ $220^{\circ} \mathrm{C}$, bath temp) gave $2.98 \mathrm{~g}(8.1 \mathrm{mmol}, 66 \%$ yield) of 4. Mass $370\left(\mathrm{M}^{+}, 6\right), 355\left(\mathrm{M}^{+}-\right.$ $15,40), 147(100) .{ }^{1} \mathrm{H}$ NMR $\left(\delta, \mathrm{CDCl}_{3}\right) 0.65$ $\left(\mathrm{s}, \mathrm{SiC}_{3}, 6 \mathrm{H}\right), 5.81$ (dd, vinyl proton, $J=$ $3,21 \mathrm{~Hz}, 2 \mathrm{H}$ ), 6.21 (dd, vinyl proton, $J=3$, $15 \mathrm{~Hz}, 2 \mathrm{H}$ ), 6.49 (dd, vinyl proton, $J=15$, $21 \mathrm{~Hz} 2 \mathrm{H}), 7.37-7.57(\mathrm{~m}$, aromatic protons, $14 \mathrm{H}),{ }^{13} \mathrm{C} \mathrm{NMR}\left(\delta, \mathrm{CDCl}_{3}\right)-4.18\left(\mathrm{CH}_{3} \mathrm{Si}\right)$, 127.90, 129.39 (vinyl carbons), 134.16, 134.88, 135.03, 135.73, 136.11, and 137.45 (aromatic carbons $),{ }^{29} \mathrm{Si} \mathrm{NMR}\left(\delta, \mathrm{CDCl}_{3}\right)-14.64$.

\section{Preparation of PCS 1a (Scheme 2)}

In a 30-ml two-neck pear-shape flask equipped with a teflon-covered magnetic stirring bar, a rubber septum and a reflux condenser were placed $4(1.16 \mathrm{~g}, 3.1 \mathrm{mmol}), 1.0 \mathrm{wt} \%$ solution of Pt complex $\left(7.54 \mu \mathrm{l}, 6.3 \times 10^{-4} \mathrm{mmol}\right)$ and toluene $(3 \mathrm{ml})$. A THF solution $(3 \mathrm{ml})$ of 5 $(0.94 \mathrm{~g}, 3.0 \mathrm{mmol})$ was added slowly by a syringe at room temperature. After the addition the mixture was stirred for $24 \mathrm{~h}$ at room temperature. The solvents were removed by evaporation under reduced pressure, and then white solid $(1.96 \mathrm{~g})$ was obtained in an isolated yield of $94 \%$. The crude product was dissolved in a minimum amount of toluene ( $c a$. $3 \mathrm{ml}$ ) and the polymer was precipitated from hexane. The polymer, $0.91 \mathrm{~g}(61 \%$ yield $)$ was dried under vacuum at room temperature. From GPC analysis, $M_{w} / M_{n}=12500 / 7000$ was obtained. ${ }^{1} \mathrm{H}$ NMR $\left(\delta, \mathrm{CDCl}_{3}\right) 0.51$ (brs, $\mathrm{SiCH}_{3}, 6 \mathrm{H}$ ), 1.00 (brs, $\mathrm{SiC}_{2} \underline{\mathrm{CH}}_{2}, 4 \mathrm{H}$ ), $7.27-7.44(\mathrm{~m}$, aromatic protons, $14 \mathrm{H})$. 


\section{Determination of the PCS 1c's Terminal Vinyl Groups}

The PCS 1c isolated by the same process as described above was dissolved in a minimum amount of $\mathrm{CHCl}_{3}(\mathrm{ca} .3 \mathrm{ml})$ and the polymer was precipitated from methyl alcohol $(82 \%$ yield). ${ }^{1} \mathrm{H}$ NMR spectrum of PCS 1c thus precipitated is shown in Figure 1. This spectrum includes 1,2-dibromoethane as an internal standard. The amounts of 1,2-dibromoethane and the precipitated PCS 1c were $2.69 \mathrm{mg}$ $(X)$ and $50.62 \mathrm{mg}(Y)$, respectively. The integral values of methylene groups of 1,2-dibromoethane and vinyl groups of the precipitated PCS 1c were $1.6(A)$ and $1.8(B)$, respectively. From the eq 1,

$$
(X / 187.9) /(Y /(370+344 n))=(A / 4) /(B / 6)(1)
$$

the number of repeated units of the precipitated PCS 1c was 13.

${ }^{1} \mathrm{H}$ NMR $\left(\delta, \mathrm{CDCl}_{3}\right) 0.57\left(\mathrm{~s}, \mathrm{SiC}_{3}\right), 0.58$ (s, $\left.\mathrm{SiC}_{3}\right), 0.66\left(\mathrm{~s}, \mathrm{SiC}_{3}\right), 0.68\left(\mathrm{~s}, \mathrm{SiC}_{3}\right)$, 1.06 (br s, $\mathrm{SiC}_{2}{ }_{2} \underline{\mathrm{H}}_{2}$ ), 3.65 (s, $\mathrm{BrC}_{2} \mathrm{CH}_{2} \mathrm{Br}$ ), 5.83 ( $\mathrm{m}$, vinyl proton), 6.23 ( $\mathrm{m}$, vinyl proton), 6.48 (m, vinyl proton), and 7.27-7.57 (m, aromatic protons).

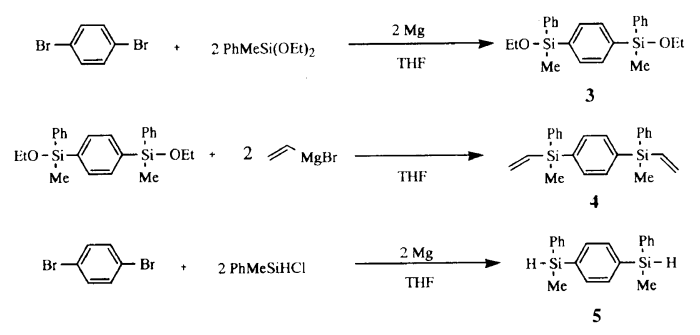

\section{RESULTS AND DISCUSSION}

\section{Monomer Synthesis}

1,4-Bis(methylphenylvinylsilyl)benzene 4 and 1,4-bis(methylphenylsilyl)benzene 5 were prepared by Scheme 3.

The reaction between $\mathrm{PhMeSi}(\mathrm{OEt})_{2}$ and 1,4-dibromobenzene exclusively afforded 1,4bis(ethoxymethylphenylsilyl)benzene 3 . The corresponding reaction of $\mathrm{PhMeSiCl}_{2}$, however, did not give 1,4-bis(chloromethylphenylsilyl)benzene at all. That is because the latter reaction was vigorous enough to partly give further-reacted products and the desirable product was easily hydrolyzed during work-up process.

\section{Hydrosilylation Polymerization between $\mathbf{4}$ and $\mathbf{5}$}

The PCS 1a-c were synthesized by hydrosilylation polymerization of bifunctional monomers (Scheme 2). The reaction proceeded quantitatively and homogeneously at room temperature. The reaction was catalyzed by $\left[\mathrm{Pt}\left\{\left(\mathrm{CH}_{2}=\mathrm{CHSiMe}_{2}\right)_{2} \mathrm{O}\right\}_{2}\right]$.

Table I summarizes the results of the polymerization. The molecular weights of PCS were successfully controlled by changing the molar ratio of $\mathbf{4 / 5}$. The number-average molecular weights $\left(M_{n}\right)$ of PCS 1 were around $1.2-7.0 \times 10^{3}$. Although the cyclic derivatives are possible to form in this reaction, we can not exclude the possibility at the present.

${ }^{1} \mathrm{H}$ NMR spectrum of the PCS $1 \mathbf{a}$ is shown in Figure 1. The resonance signals at 0.51, 1.00, and $7.24-7.44 \mathrm{ppm}$ are assigned to methyl,

Scheme 3.

Table I. Hydrosilylation polymerization ${ }^{a}$ between $\mathbf{4}$ and $\mathbf{5}$

\begin{tabular}{ccccccc}
\hline Run & & $\mathbf{4} / \mathbf{5}^{\mathrm{b}}$ & Solvent $[\mathrm{M}]^{\mathrm{c}}$ & Reaction condition & $M_{n}\left(M_{\boldsymbol{w}} / \boldsymbol{M}_{n}\right)^{\mathrm{d}}$ & Yield $/ \%^{\mathrm{e}}$ \\
\hline 1 & 1a & 1.1 & Toluene $(1.0)$ & r.t. $24 \mathrm{~h}$ & $7000(1.8)$ & 61 \\
2 & 1b & 1.3 & Toluene $(0.9)$ & r.t. $24 \mathrm{~h}$ & $5900(1.7)$ & 45 \\
3 & lc & 1.5 & Toluene $(1.0)$ & r.t. $/ 4$ h $-85^{\circ} \mathrm{C} / 4 \mathrm{~h}$ & $1200(1.8)$ & 82
\end{tabular}

${ }^{a}$ The platinum catalyst $\left[\mathrm{Pt}\left\{\left(\mathrm{CH}_{2}=\mathrm{CHSiMe}\right)_{2} \mathrm{O}\right\}_{2}\right]\left(1 \times 10^{4}\right.$ equiv rel to the vinyl substituents $) .{ }^{\mathrm{b}}$ Molar ratio of 4 and 5. ${ }^{\mathrm{c}}$ Concentration of monomers. ${ }^{\mathrm{d}}$ Relative values to polystyrene standards obtained by GPC detected on RI after precipitation. ${ }^{\mathrm{e}}$ The values after precipitation. 
Polycarbosilanes Synthesized by Hydrosilylation
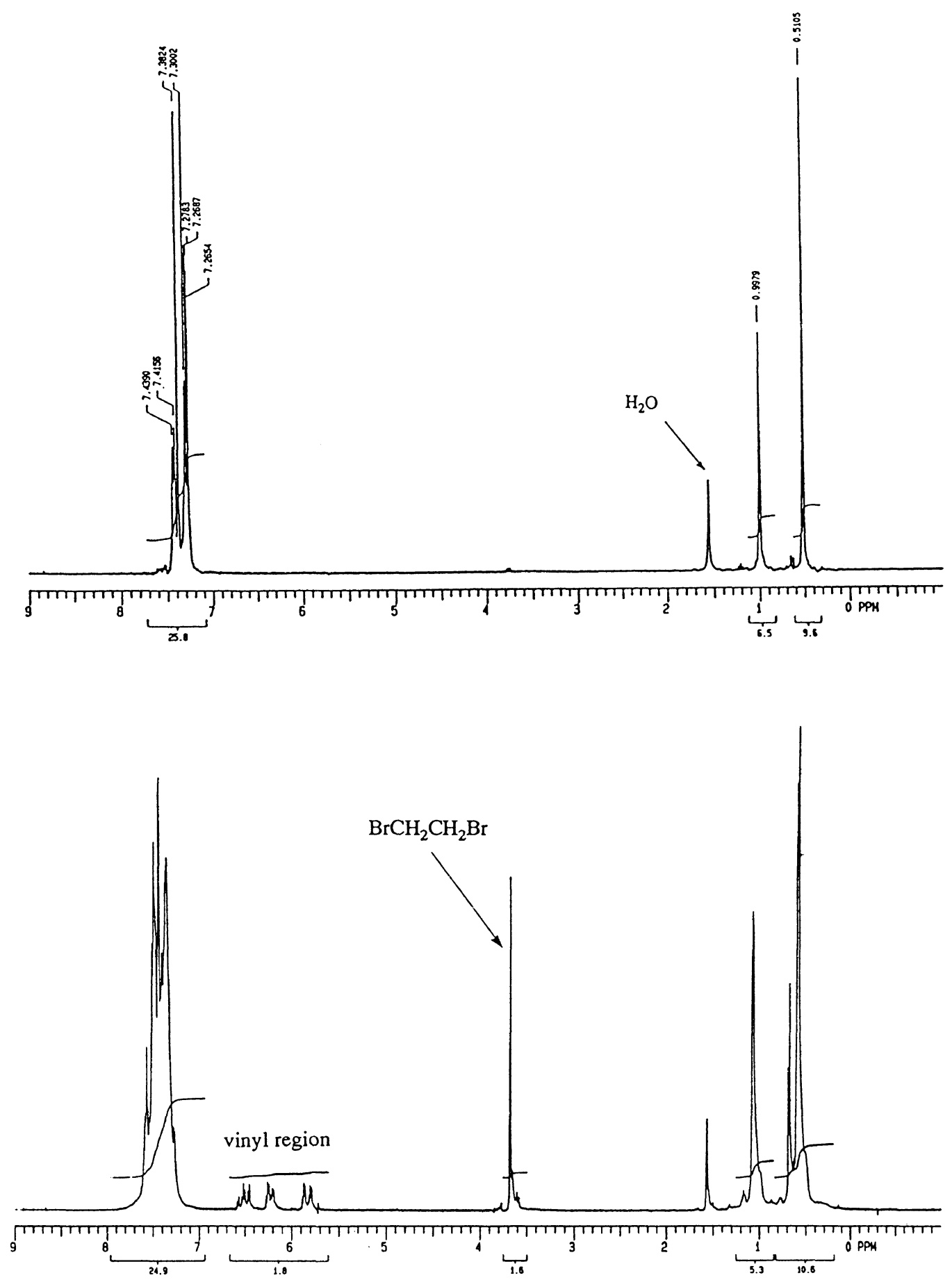

Figure 1. $400 \mathrm{MHz}{ }^{1} \mathrm{H}$ NMR spectra of PCS in $\mathrm{CDCl}_{3}$ (upper, PCS 1a, lower, PCS 1c in the presence of $\mathrm{BrCH}_{2} \mathrm{CH}_{2} \mathrm{Br}$ ). 
methylene, and aromatic groups, respectively. The integral ratio of methyl groups/methylene groups/aromatic groups of PCS 1a, $3 / 2 / 8$, was almost equal to the calculated value, $3 / 2 / 7$. Thus the polymerization reaction proceeded quantitatively with $\beta$-addition regioselectivity, and the PCS 1 a actually is composed of $[-(\mathrm{Ph})-$ (Me)Si-p- $\left.\mathrm{C}_{6} \mathrm{H}_{4}-(\mathrm{Ph})(\mathrm{Me}) \mathrm{Si}-\mathrm{CH}_{2} \mathrm{CH}_{2}-\right]$ as repeated units.

Vinyl end-blocked polycarbosilane 1c was prepared from excess (1.5 equiv) amounts of vinylsilane monomer 4. The vinyl functionality of the precipitated PCS 1c could be clearly identified by ${ }^{1} \mathrm{H}$ NMR as shown in Figure 1. From the calculation by internal standard, the number of repeated units of PCS 1c was 13 $\left(M_{n}=4800\right.$, see EXPERIMENTAL). This calculated value was larger than the observed value by GPC $\left(M_{n}=1200, n=4\right)$. Thus the absolute molecular weight of PCS 1c might be larger than the observed one by GPC; for example, the absolute molecular weights by light-scattering of polysilanes, regarded as one of the silicon-based polymers, were reported larger by $2-3$ times than the values by GPC. ${ }^{11}$ It was also clear that the vinylsilane monomer 4 in the precipitated PCS 1c was partially left by GPC analysis ( $c a .5 \%)$. The cause of the monomer remaining may be explained by probability; roughly speaking, the probability of the vinyl functionality unreacted should be $1 / 9(1 / 3 \times 1 / 3)$ if the reactivity is constant during the reaction.

The PCS 1c can be further applied for a crosslinking system with a multi-functional $\mathrm{SiH}$ compound by hydrosilylation ${ }^{12}$. The synthetic route may prove a useful route to give a vinylend blocked polycarbosilanes with controlled molecular weights, whereas Znamenskaya's route $^{2}$ did not provide such a controlled polymer.

\section{Physical Properties of Polycarbosilane 1a}

Table II summarizes the physical properties of PCS 1a compared with PCS 2.

It was clear that the solubility of PCS 1a in an organic solvent was much better than that of PCS 2. We considered the reason why the PCS 1a was composed of Si atom of chiral center to decrease the crystallinity. The lower melting point of PCS 1a was caused by the lowering of the crystallinity. The similar effect was reported in the case of polysilanes; $(\mathrm{PhMeSi})_{n}$ was soluble in organic solvents whereas $\left(\mathrm{Me}_{2} \mathrm{Si}\right)_{n}$ was insoluble in organic solvents. ${ }^{13,14}$

The thermal stabilities of PCS 1a and PCS 2, both of which have almost the same

Table II. Physical properties of polycarbosilanes

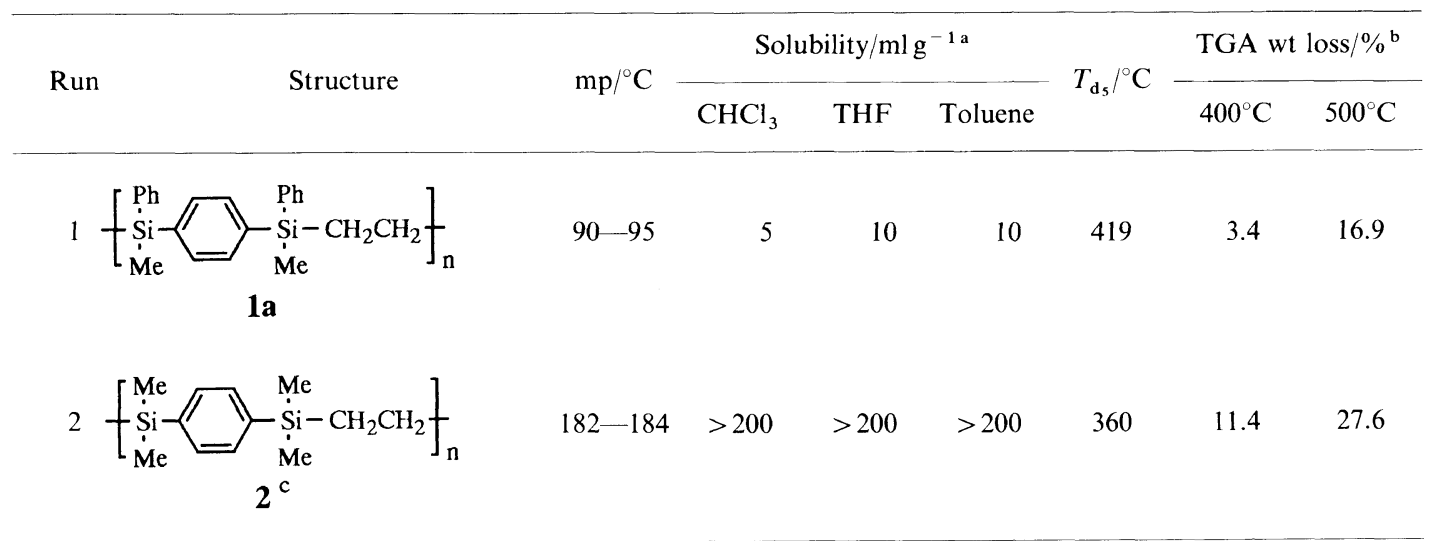

${ }^{\mathrm{a}}$ Minimum solvent volume required for dissolving $1 \mathrm{~g}$ of the polymer at $15-20^{\circ} \mathrm{C}$. ${ }^{\mathrm{b}} \mathrm{Under}^{\mathrm{N}} \mathrm{N}_{2}, 20^{\circ} \mathrm{C} / \mathrm{min}^{-1}$. ${ }^{\mathrm{c}} M_{n}=7300\left(M_{w} / M_{n}=1.7\right)$. 
molecular weight $\left(M_{n} \fallingdotseq 7000\right)$, are shown in Table II together with their TGA curves in Figure 2. It was clear that PCS 1a was more stable than PCS 2 over the $300-500^{\circ} \mathrm{C}$ region, which is easily recognized from the TGA curves. The thermal degradation of the polycarbosilanes seems to be caused by the elimination of substituent groups. In general, thermal degradation of polycarbosilanes mainly have two pathes; one is elimination of substituent groups and the other is decomposition of backbone. Provided the decomposition of the backbone of PCS is more predominant and the mechanism of the two polymers' decomposition are the same, the $(\mathrm{Ph})(\mathrm{Me}) \mathrm{Si}$ units in PCS 1a will be eliminated and will be the $\mathrm{Me}_{2} \mathrm{Si}$ units in PCS 2 . As a result, PCS 1a should be less stable than PCS 2 . These results, however, are not consistent with experimental data (Table II). Accordingly, the elimination of the substituent groups of PCS must be more probable than the decomposition of the backbone. Moreover, the elimination of $\mathrm{Me}$ groups of PCS 2 is more likely than that of $\mathrm{Ph}$ groups from an estimation based on the bond energies previously reported. ${ }^{15}$ If the all methyl groups (two per unit of PCS 1a and four per unit of PCS 2) are eliminated, the weight loss

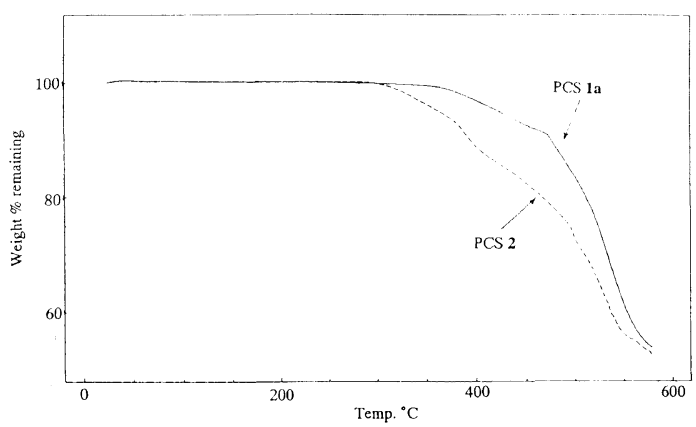

Figure 2. TGA curve of PCS 1a and PCS 2 under nitrogen stream. will be calculated 9\% (PCS 1a) and 27\% (PCS 2), respectively. These calculation results seem to be consistent with experimental data (Table II). We are now under way for clarifying thermal degradation behavior of PCS 1a and PCS 2 by Pyrolysis-Gas Chromatografy.

Acknowledgments. This work was performed by Kaneka Corporation, under the management of the Japan High Polymer Center as part of Industrial Science and Technology Frontier Program supported by New Energy and Industrial Technology Development Organization.

\section{REFERENCES}

1. J. W. Curry, J. Am. Chem. Soc., 78, 1686 (1956).

2. E. N. Znamenskaya, N. S. Nametkin, N. A. Pritula, V. D. Oppengeim, and T. I. Chernysheva, Neftekhimiya, 4, 487 (1964).

3. Y. Pang, S. Ijadi-Maghsoodi, and T. J. Barton, Macromolecules, 26, 5671 (1993).

4. P. R. Dvornic and V. V. Gerov, Macromolecules, 27, 1068 (1994).

5. P. R. Dvornic, V. V. Gerov, and M. N. Govedarica, Macromolecules, 27, 7575 (1994).

6. G. Chandra, P. B. Hitchcock, M. F. Lappert, and P. Y. Lo, Organometallic's, 6, 191 (1987).

7. P. B. Hitchcock, M. F. Lappert, and N. J. W. Warhurst, Angew. Chem., Int. Ed. Engl., 30, 438 (1991).

8. K. Ando, J. Kotani, T. Iwahara, and K. Yonezawa, Jpn. Kokai Tokkyo Koho JP06, 287308 (1994).

9. L. W. Breed and R. L. Elliott, J. Organomet. Chem., 9, 188 (1967).

10. N. S. Nametkin, N. A. Pritula, and T. I. Chernysheva, "Sintez i Svoisiva Monomerov," Akad. Nauk SSSR, Inst. Neftekhim. Sinteza, Sb. Rabot 12-oi [Dvenadtsatoi] Konf. po Vysokomolekul. Soedin., 1962, p 97.

11. R. West, Journal of Organometallic Chemistry, 300, 327 (1986).

12. This will be published elsewhere

13. J. D. Wesson and T. C. Williams, J. Polym. Sci., Polym. Chem. Ed., 18, 959 (1980).

14. R. E. Trujirllo, J. Organomet. Chem., C27, 198 (1980).

15. R. Walsh, Acc. Chem. Res., 14, 246 (1981). 